\title{
Enhancing Recreation Sustainability through Social Capital Development
}

\author{
Mindi Lehew ${ }^{1, *}$, Randy Gimblett ${ }^{2}$, Francisco Valenzuela ${ }^{3}$ \\ ${ }^{1}$ United States Forest Service, Coronado National Forest, Santa Catalina Ranger District, USA \\ ${ }^{2}$ School of Natural Resources and Environment, University of Arizona, USA \\ ${ }^{3}$ United States Forest Service, Southwestern Region, USA
}

Copyright $(\mathcal{C} 2015$ by authors, all rights reserved. Authors agree that this article remains permanently open access under the terms of the Creative Commons Attribution License 4.0 International License

\begin{abstract}
Recreation areas represent a socio-ecological system in which the primary purpose is to sustain the ecologic functions of the environment while also providing satisfying recreation experiences. Sustainability in a recreation area requires that the components that support this system are maintained or increased over time. These components can be thought of as 'capital'. The focus of this study, social capital, examines the human element of this system by recognizing the potential value added by the visitor in terms of overall sustainability. The goal of this research was to measure the potential to build social capital amongst the visitors in the Sabino Canyon Recreation Area (SCRA) of the Coronado National Forest, United States, as a means of contributing to the overall sustainability of the recreation area. Recreation visitors were surveyed to determine their values surrounding the SCRA. The survey results defined visitor values by their willingness to devote time and finances, respect for the environment and resources, and actual statements of value. Based on responses to the survey questions, each respondent's relationship with the SCRA was characterized as contributing to the system's sustainability, having no effect, or reducing its sustainability. Fundamental features of social groups that allow individuals to work together for a common purpose are present at SCRA. By uniting visitors around their shared values, managers may be able to catalyze the collective efforts of social groups to foster a mutual commitment to the sustainability of the SCRA.
\end{abstract}

Keywords Sustainability, Social Capital, Resource Management, Resilience, Conservation, Recreation

\section{Introduction}

Recreation experiences are the primary way for Americans to connect with their public lands. Recreation experiences in special places often inspire conservation ethics, personal values and responsibility that can translate into lifelong environmental stewardship and advocacy. Rapidly growing demand for these opportunities has challenged existing recreation programs that face increasingly limited budgets and resources. To better serve the American public, land management agencies must develop new management models that maintain high quality recreation opportunities and expand the capacity of managed environments to provide these vital benefits. The complex interactions between the economy, environment, and society require resource managers to seek out ways to enhance the components that comprise these systems to build sustainability and resiliency into public recreation areas.

A public recreation area such as SCRA can be viewed as a socio-ecological system. The purpose of this system is to sustain the ecologic functions of the environment while also providing satisfying recreation experiences to society. Sustainability in a recreation area requires that the components that support this system are maintained or increased over time. The components of this system include elements of natural, built and social capital. Natural capital comprises the goods and services provided by natural ecosystem functioning. Built capital in a recreation area includes supporting facilities and infrastructure. Social capital, in the context of this research, refers to the features of social organizations that facilitate collective actions to produce mutual benefits. Together, the three types of capital support continued recreation opportunities for the public in a healthy, natural environment.

Existing models of recreation management often view visitors as a source of negative impacts which degrade the natural environment and the recreation experience. The sustainable recreation management model considers the visitor as a potential source of system adaptability. Under this new model, managers assert that visitors have the potential to increase the capability of the system to both protect the natural environment and provide high quality recreation experiences.

This paper explores the concept of social capital and its 
relationship to sustainability by examining the values and behaviors of visitors in the SCRA. Because recreation areas are intended for public use, visitors may be the most important factor for the long-term sustainability of this particular kind of system. There is a great need to better understand the influence of social capital on recreation areas and to evaluate the effectiveness of this model for recreation managers. This research hypothesizes that a recreation area is more likely to be sustainable and resilient if the area has high levels of social capital because the visitors are more likely to behave in ways that collectively support and enhance the purpose of the recreation area, both inside the area and in the larger community.

Previous research efforts surrounding social capital theory have experienced difficulty in measuring the critical components of social capital, such as values, networks and trust (Collier 2002; Daniere et al. 2002; Liu and Besser 2003; Narayan and Cassidy 2001). In addition, there have been no efforts to explore practical applications of social capital to recreation management. From a practical perspective, methods must be relatively inexpensive and have predictive validity if they are to be useful for recreation managers. This assessment of social capital in recreation areas is based on the assumption that visitors who have shared environmental values may be willing to work together to support the purpose of the SCRA.

\section{Background}

In the changing culture of natural resource management, managers must enhance their ability to maintain the ecosystem services that support recreation programs by capitalizing on the capacity of those people who value these areas. Managers must actively expand their decision-making process by inviting local communities and user groups that participate in recreation programs to participate in the stewardship of these special places (Poe \& Gimblett 2015). Diminishing federal budgets no longer allows agencies to provide opportunities for quality recreation independent of community support. Local communities also face similar financial challenges and mutually rely on support from recreation managers to administer programs and sustain ecosystem services that contribute to their economic health and resiliency (Poe \& Gimblett 2015).

Managers must address the growing disconnect between citizens and nature that has resulted from our nation's increased urbanization. The societal shift that now trends toward technology and media for entertainment and information has limited people's exposure to natural landscapes. As cities begin to encroach on natural environments, recreation areas experience additional pressures on facilities and services. These facilities and recreation settings have steadily degraded over time, creating an unmanageable workload for the existing agency workforce (USDA 2010a).

Managers of these landscapes must actively reconnect the public to its natural and cultural heritage to inspire stewardship and responsibility for the land. All of these issues pose difficult questions and force managers to create implementable programs that minimize negative impacts to the environment while also considering the implications for society (Poe \& Gimblett 2015). As visitors to recreation areas grow to appreciate and value the land, managers can harness the capacity of these passionate individuals to work together to collectively solve problems and accomplish goals that support and sustain public recreation.

The Forest Service has responded to these current challenges through the creation of the Framework for Sustainable Recreation (the Framework), a document that presents strategic guidance for recreation professionals. This framework directs managers to focus on community engagement and incorporate social, environmental and economic considerations into management decisions (USDA 2010b). The agency design highlights sustainability through the intersection of the three "spheres of sustainability" - the environment, society and the economy (USDA 2010b). This framework guides the analysis of existing programs and provides general direction for implementation on a regional and forest-wide scale.

By emphasizing the interconnectedness of social and ecological systems, sustainable recreation offers a unique approach to solving management challenges (Poe \& Gimblett 2015). The foundation for this concept has been rooted in sustainability science, collaborative planning and conflict resolution, with applications that promote overall landscape connectivity (USDA 2012a). Recreation is understood as an ecosystem service that benefits society and natural resource management as a form of resilience-based ecosystem stewardship (Chapin et al. 2009). The long-term goals of the Framework are to sustain public lands and the outdoor opportunities that those lands provide for people to form a stewardship relationship with nature.

The Framework for Sustainable Recreation offers a creative solution to current recreation challenges by "providing desired benefits through the science of recreation management for present and future generations" (Valenzuela 2013). The general guidelines provided by the national framework must be adopted at many scales, from regional landscapes to individual recreation areas. To manage a successful recreation programs, managers must adopt a holistic approach that focuses on recreation's most important contributions to forests and communities. The Framework suggests a focus on the intersection of economic, social and ecological values to achieve sustainability. Sustainable recreation must clarify its role in ecosystem stewardship so that recreation use can continue while public land ecological condition and resiliency is increased. The overall objective of sustainable recreation must center on recreation's positive contribution to the sustainability of public lands by providing enduring benefits for present and future generations (Valenzuela 2013). For the purposes of this study, sustainability refers to the ability to maintain or improve the productive base that supports recreation over time. This 
productive base includes the dynamic elements of society, the environment and the economy, that interact within a recreation area and support the goal of the socio-ecological system.

\section{Sustainability through Society}

This study focuses on the social sphere presented in the Framework for Sustainable Recreation (See Figure 1). A sustainably functioning recreation system is important for society because it will: help managers to work more efficiently, enrich the visitors' recreation experience and maintain quality opportunities for public enjoyment into perpetuity. Considering the potential value of the visitor as a contributor to resiliency, recreation managers should develop means to quantify this value and organize networks of individuals that share a common desire to see these opportunities and areas prosper through time.

Sustainability in the social dimension must be evaluated using a responsive metric system that allows managers to gauge the effectiveness of the sustainable recreation concept. Outputs must be measureable and indicative of successes and the agency must have the capacity to collect and interpret the necessary data (USDA 2012c). Commonly suggested indicators of sustainability in the social sector are: quality of relationships, demonstrated public interest in collaboration, increased partner involvement, and willingness to support recreation projects.

As a socio-ecological system, recreation areas are increasingly reliant on a base of contributory visitors to fulfill the intended purpose of this system. If recreation managers are to capitalize on the values carried by the visitor, they must explore potential opportunities to quantify these values and learn from other disciplines that have embraced human networks as an asset to success. The concept of social capital has been applied in a variety of disciplines, ranging from sociology to economics, as a means to study the productive benefits that result from social relationships and the values shared between people (Claridge 2004; Robison et al. 2002). The interaction of social capital and recreation has not yet been explored in academia or in practice and therefore requires its own unique characterization.

\section{Defining and Measuring Social Capital}

Social capital theory was popularized by early economists such as Pierre Bourdieu, James Coleman and Robert Putnam. Although authors and practitioners in social capital theory have debated over the definition of this term, applications have proven that social capital is highly context-specific and may not lend to a single consensus definition (Robison et al. 2002). Despite the variety of interpretations, the central premise of social capital is that certain features of social organizations, such as values and networks, facilitate collective actions to produce shared benefits (Putnam 1995). In this way, social capital can have importance for both the members within these networks and the partners that engage with these groups (Putnam 2003). General definitions found in economics and sociology continually reference the key features of social interactions - shared values, norms, attitudes, beliefs - that predispose people towards mutually advantageous actions (Krishna and Uphoff 2002).

Adler and Kwon (2002) describe social capital as "the goodwill available to individuals or groups" that serves as a valuable resource in building a sustainable social system. Other authors, such as Boxman et al. (1991), argue that social capital is defined by "the number of people who can be expected to provide support, and the resources those people have at their disposal". The most elementary definitions describe social capital as "the ability of people to work together for a common purpose"; this ability is supported by the set of values shared among members that allows them to partner effectively (Fukuyama 1997). The key to understanding the application of social capital in any setting is to present a clear definition that is germane to the specific discipline, context and study in question. This paper defines social capital as the features of social organizations that facilitate collective actions to produce mutual benefits.

Much of the current literature discusses the significant challenges associated with measuring social capital, in regards to feasibility, practicality, and linking metrics back to the conceptual theory (Grootaert et al. 2002). Solutions offered in the literature suggest that researchers should identify relevant indicators to evaluate social capital at the foundational rather than theoretical level (Collier 2002). According to Murdock (2012), the two primary criteria for relevant indicators are that they must be measurable and manageable. For these indicators to apply to social capital, they must be within the scope of the researcher or practitioner's control to monitor and manipulate over time. Rather than directly measuring social networks, we found it more feasible to focus on the characteristics of the individual that prompts a single member to join a like-minded group. As discussed earlier, these characteristics are the most fundamental features of social organizations.

\section{Social Capital and Natural Resource Management}

There have been several applications of social capital theory in natural resource management, although these studies are limited compared with the wealth of traditional applications in economics and governance. Natural resource agencies and institutions have shown an increasing interest in partnering with community groups to solve local resource issues, ranging from resource degradation to budgetary challenges (Grootaert et al. 2002). General studies have shown that social capital has a beneficial effect on the capacity of individuals with shared values to come together to act in support of a common purpose. In the realm of environmental conservation and land management, social capital has been shown to reduce the costs of collective actions, increase information flows and idea-sharing, contribute to environmental conflict resolution, and improve the overall management of common pool resources (Cavaye 2004). Many natural resource studies have emphasized the 
need for leaders or influential players to activate social capital amongst communities that rely heavily on environmental systems. These catalyzing agents are often an important mechanism for producing shared benefits that sustain both the community and the environment (Bodin and Crona 2008).

The organization of participatory groups to improve environmental management has been achieved in fishing communities, rural land management cooperatives, watershed partnerships, and a variety of sustainable development enterprises (Pretty and Ward 200; de Wit and Blignaut 2000, Compton and Beeton 2012; Henocque 2013). The measured benefits of social capital for natural resource management are often cited as increasing cooperation and support, securing more investment in shared lands, and generally accomplishing more as a collective whole than individuals working alone (Pretty and Ward 2001). In the natural resources context, social capital has served as an indication of the community's potential to jointly address local problems associated with environmental management (Pilkington 2002; Ritchie 2000). Social capital also presents an opportunity to link national policies like the Framework for Sustainable Recreation with community level actions such as those suggested in this research (Pretty and Ward 2001).

\section{Conceptual Framework}

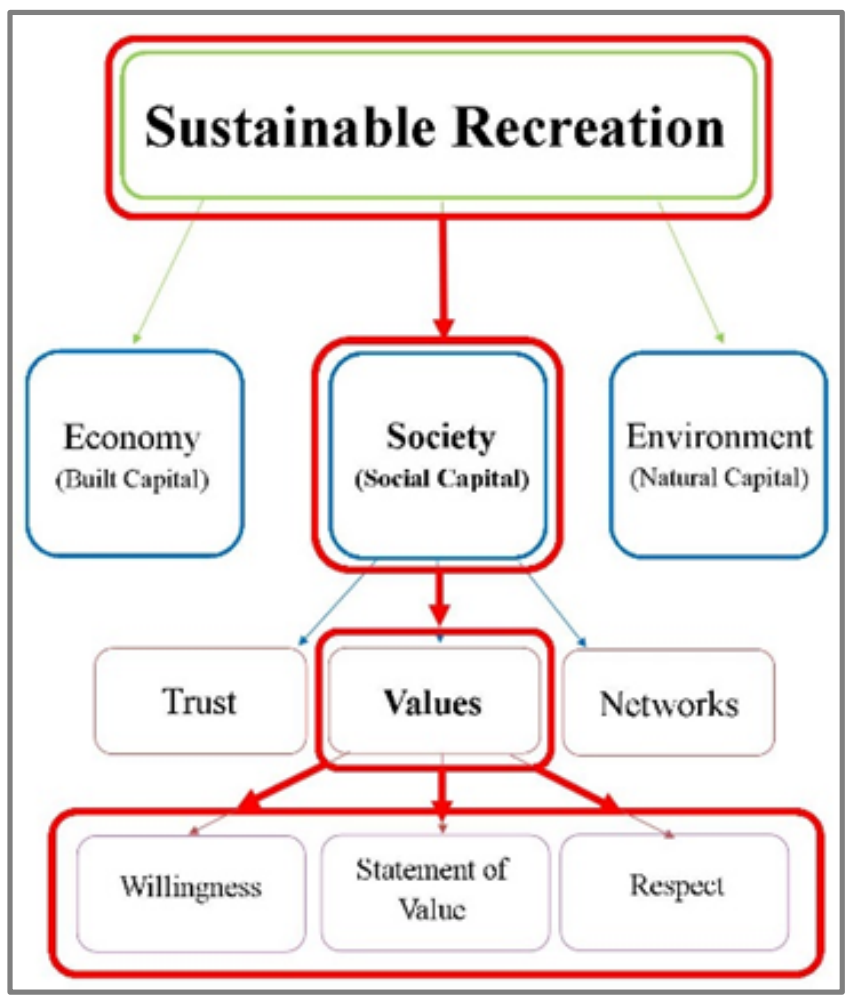

Figure 1. Conceptual Framework
We have developed the following conceptual framework to guide this research and to illustrate the hierarchy of concepts addressed in this study (Figure 1). This graphic provides a visual explanation of the process used to develop indicators and measures of social capital and its connection to overall sustainability in recreation. Sustainable Recreation is placed at the top of the graphic because it serves as the overarching concept composed of the economy, society, and the environment. This study focuses specifically on the social element of Sustainable Recreation, using social capital to represent this sector. Social capital is commonly measured by examining features such as trust, values, and networks (Narayan and Cassidy 2001). This research effort looks primarily at values as defined by willingness, statements of value, and respect.

The goal of this research is to measure the potential to build social capital amongst the visitors currently recreating in the Sabino Canyon Recreation Area as a means of contributing to the overall sustainability of the place and its recreation opportunities. The following research questions and objectives were established to guide this study. Research questions are as follows:

1. Is there a tangible connection between social capital and sustainability?

2. Can the concept of social capital be applied to natural resource management, specifically in the context of recreation?

3. What are the components of social capital that can be measured and how?

4. Is there potential to build social capital in the group that currently uses Sabino Canyon?

The Study Area

This study focused on visitors using the 1,423-acre Sabino Canyon Recreation Area (SCRA) located within the Santa Catalina Ranger District on the Coronado National Forest in southeastern Arizona, adjacent to the Tucson metropolitan area. The SCRA serves as a popular recreational gateway into the nearby Pusch Ridge Wilderness and Santa Catalina Mountains. The SCRA also hosts a visitor center and a shuttle system that offers natural resource interpretation on a scenic drive through Sabino Canyon. The peak visitation season at the SCRA falls between the months of November and April, with lower visitation in the summer months. Of the 18 trails originating in the SCRA, the majority extend beyond the boundary of the designated recreation area into the Pusch Ridge Wilderness and Santa Catalina Mountains.

With an estimated 1.25 million visitors every year, the SCRA represents a convergence of many forms of recreational use and serves as the most visited site on the Coronado National Forest (PLIA 2011). The primary types of visitor use in the SCRA include hiking, walking, running, shuttle riding, picnicking, wildlife observation, photography and nature study. The canyon has several intermittent and flowing water sources, which attract recreationists seeking refuge from the desert heat. 


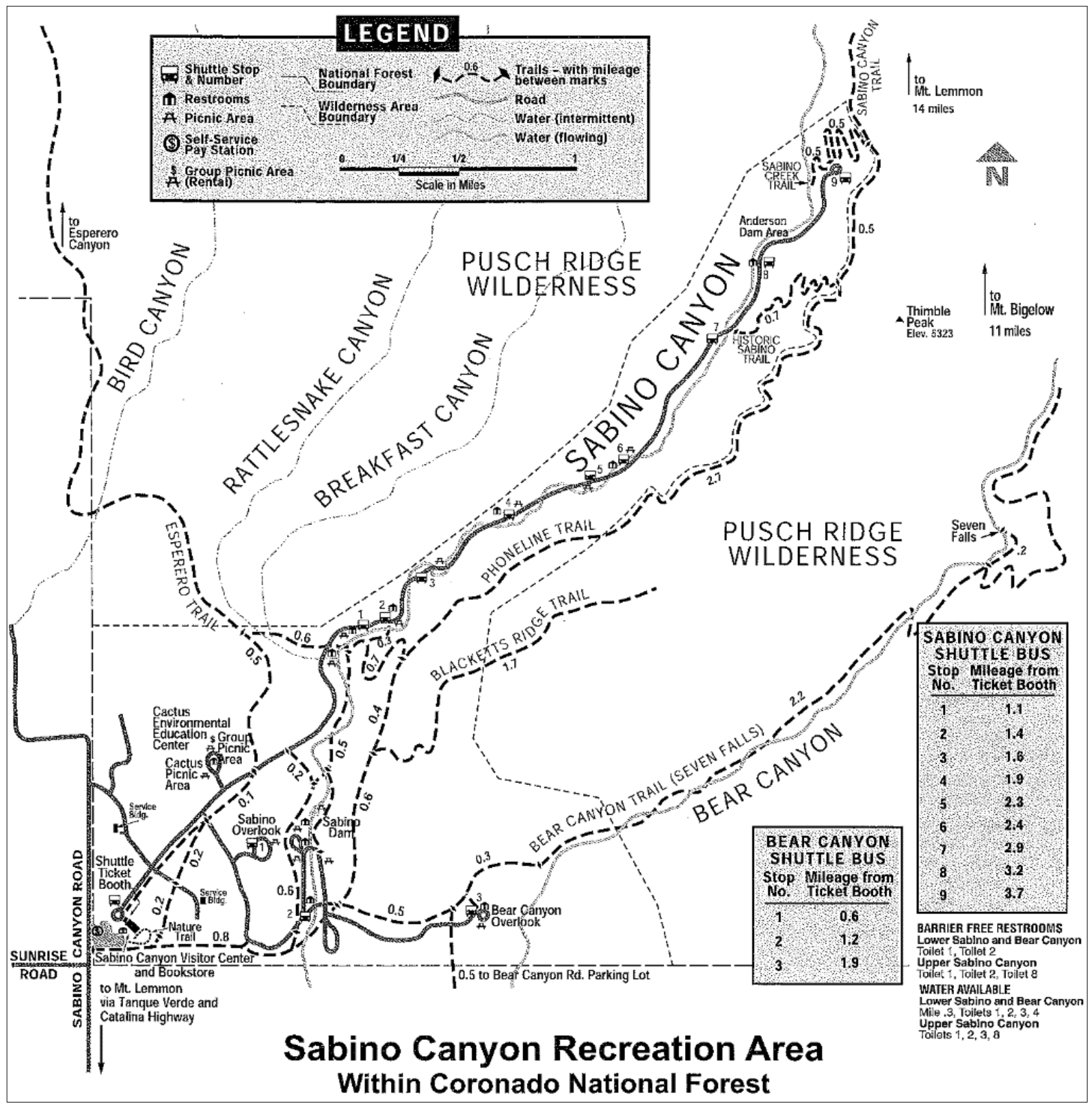

Figure 2. Map of the Sabino Canyon Recreation Area

\section{Methods}

To achieve a comprehensive assessment of the potential for social capital development at Sabino Canyon, a 14-question multiple-choice survey was developed and administered both in-person using an approved script and through an online survey. We stratified the survey sample into three primary groups that frequent the recreation area: random visitors among the general public (hikers, runners, cyclists, and general nature enthusiasts), members of designated partner and volunteer organizations (non-profit organizations and recreation clubs), and Tucson-area Forest Service employees that help manage the SCRA.
All respondents in this study were approached at random such that each individual had an equal chance of being selected for participation during the sampling process. Similarly, the online survey was distributed to the complete electronic mailing list of all Forest Service employees at the Santa Catalina Ranger District and Supervisor's Office, both located in Tucson, Arizona. The same online survey was distributed to the electronic mailing list for the Sabino Canyon Volunteer Naturalists, the Sabino Canyon Volunteer Patrol, and the Friends of Sabino Canyon - all partner organizations directly associated with the SCRA.

The total population size that was offered participation or approached in this study included $n=122$ Forest Service 
employees, $\mathrm{n}=300$ volunteers and partners, and $\mathrm{n}=379$ members of the general public. Of this population, the final sample of respondents included $\mathrm{n}=61$ Forest Service employees, $\mathrm{n}=21$ volunteers and partners, and $\mathrm{n}=369$ members of the public. A total of $n=451$ surveys were obtained at the completion of this study.

The survey was developed through communication with both Forest Service managers and recreation professionals beginning in the spring of 2013. In these discussions, we identified the primary factors of social behavior that could be measured and would reveal personal values about the SCRA either directly or indirectly. The survey questions were designed in response to some of the central questions presented by the Framework for Sustainable Recreation, focusing specifically on the society component of the three "spheres of sustainability". The five categories of substance questions were developed based on indicators of social capital and the critical components that comprise a sustainable socio-ecological system. These five categories include:

- the natural resources that comprise the physical environment that supports recreation opportunities,

- the visitors' past experiences that shaped their values and attitudes toward the environment,

- the contributions that visitors would be willing to make to help protect, restore and enhance the natural resources and recreation facilities at the SCRA,

- the social responsibility of each individual to personally respect the environment and report any disrespectful behavior,

- the admitted values that visitors hold for the SCRA and its contribution to their quality of life

The substance questions within these five categories were designed to avoid language or wording that may lead the participant to believe there was a right or wrong answer to the question. Because the goal of this survey was to evaluate the individual's potential contribution to social capital in the SCRA, each question had three types of responses. Each response was designed to characterize the individual's relationship with the SCRA, indicating that the visitor had either a (1) negative, (2) neutral, or (3) positive relationship with the SCRA. This prearranged numeric coding system for each response was later used to facilitate a simplified data entry and analysis process. Although each response was developed with an assigned relationship value in mind, the responses were written to appear neutral without an obvious correct answer. The intent of this design was to encourage honesty in visitor responses and to avoid bias or leading language toward a perceived "right" answer.

The initial email sent to solicit participation from Forest Service employees and members of partner organizations was distributed on November 21, 2013. A second email was sent on December 16, 2013 to encourage additional participation amongst these groups and to notify participants of the closing date for the survey. The online survey was open from November 21, 2013 until January 2, 2014. All of the in-person surveys were distributed and collected on November 29, 30 and December 1, 2013 between 8:00am and $4: 30 \mathrm{pm}$, in conjunction with the operating hours of the visitor center.

For this study, value was defined by the willingness to devote time and finances, respect for the environment and resources, and actual statements of value. Each respondent's relationship with the SCRA was defined by their responses to the survey questions. These relationships were then characterized overall as positive, neutral or negative. Based on the type of relationship, each person either contributes to the system's sustainability, has no effect, or reduces its sustainability. A Social Capital Scale was created to identify where each respondent fits along a negative to positive relationship gradient (Figure 3). The possible range of responses was designed to resemble a modified Likert scale. Negative responses were given 1 point, neutral responses were given 2 points, and positive responses were given 3 points. With ten substance questions on the survey, the lowest possible score was 10 and the highest possible score was 30 . Overall scores in the range of 10-16 points resulted in a negative relationship. Overall scores in the range of 17-23 points indicated a neutral or passive relationship. Finally, those individuals who scored between 24-30 points overall were characterized as having a positive relationship with the SCRA that contributes to the area's sustainability.

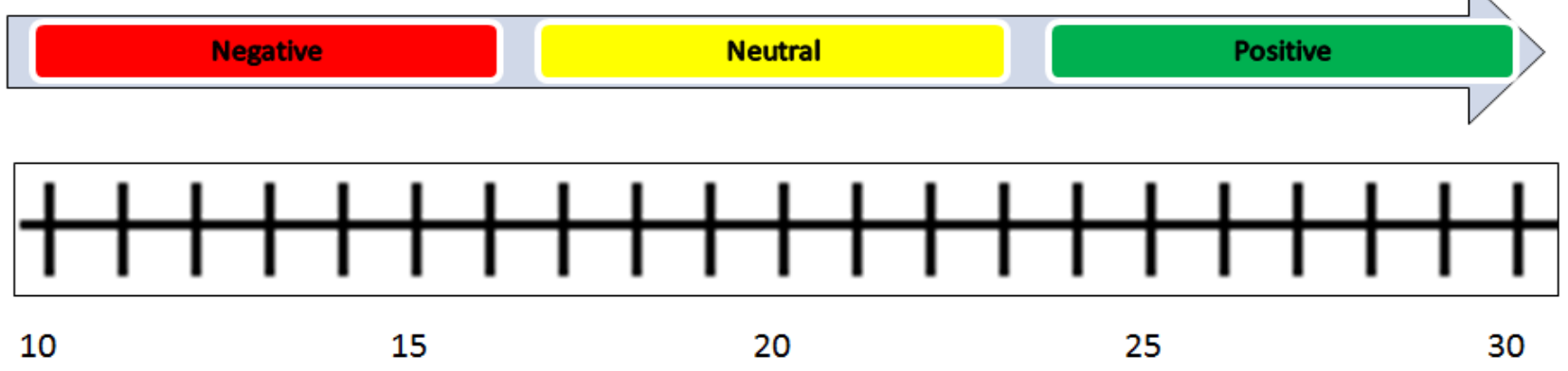

Figure 3. The Social Capital Scale 
All survey responses were numerically coded as (1), (2), or (3) based on the characterization of their response as negative, neutral or positive. All socio-demographic information was recorded as the exact response, rather than using a numeric coding system. All responses were organized in columns by question. All data were entered into a Microsoft Excel spreadsheet and then formatted for analysis in a statistical software program called Stata. Statistical analysis was divided into two sections: descriptive and inferential statistics. Descriptive statistics including mode and median were used to describe the data set. Inferential statistics, specifically Pearson's chi-squared tests, were used to characterize the significance of different responses between user groups.

\section{Results}

Of the $\mathrm{n}=451$ surveys completed, the majority of surveys collected $(85 \%)$ were distributed in person, with $15 \%$ of surveys completed online. The in-person surveys had a substantially higher response rate $(97 \%)$ than the online surveys $(19 \%)$.

From a total of $n=451$ surveys completed, the majority of respondents $(81.8 \%)$ were members of the general public visiting Sabino Canyon. Forest Service employees made up $13.5 \%$ of the respondents and partners comprised the remaining $4.7 \%$ of total participants.

The null hypothesis was that the opinion of respondents was independent of their group classification (e.g. public, partner, or Forest Service). The alternative research hypothesis was that there was a statistically significant association between the user group affiliation and the respondent opinions (Corder and Foreman 2009). The results of statistical testing show that in the majority of survey questions (71.4\%), we can reject the null hypothesis and fail to reject the alternative research hypothesis because there was a statistically significant association between the user group affiliation and the respondent opinions.

The following tables display the results of the $n=451$ surveys collected in this study. Table 1 presents the complete summary of survey responses to the 10 substance questions. Table 2 presents the complete summary of survey responses to the four socio-demographic questions. Responses to socio-demographic questions provided background information to inform the interpretation of the participant responses to the 10 substance questions. These responses did not factor into the scores on the Social Capital Scale.

Table 1. Summary of Survey Responses: Substance Questions (* $=$ statistically significant)

\begin{tabular}{|c|c|c|c|c|c|}
\hline$\#$ & Question & Responses & No. & $\%$ & p-value \\
\hline 1 & $\begin{array}{l}\text { Which statement best describes your travel patterns at the } \\
\text { Sabino Canyon Recreation Area (SCRA)? }\end{array}$ & $\begin{array}{l}\text { Travel off-trail } \\
\text { Mostly stay on trails } \\
\text { Always stay on trails }\end{array}$ & $\begin{array}{c}11 \\
193 \\
247\end{array}$ & $\begin{array}{c}2.44 \\
42.79 \\
54.77\end{array}$ & $0.060^{*}$ \\
\hline 2 & $\begin{array}{l}\text { If you were to encounter unique wildlife in the SCRA (e.g. } \\
\text { deer, javelina, birds), would you: }\end{array}$ & $\begin{array}{l}\text { Move in closer } \\
\text { Take a picture } \\
\text { Tell your friends }\end{array}$ & $\begin{array}{c}85 \\
262 \\
104\end{array}$ & $\begin{array}{l}18.85 \\
58.09 \\
23.06\end{array}$ & $0.052 *$ \\
\hline 3 & $\begin{array}{c}\text { How many environmental education or interpretation } \\
\text { programs have you participated in, either at the SCRA or } \\
\text { elsewhere? }\end{array}$ & $\begin{array}{c}\text { None } \\
1-2 \\
\text { More than two }\end{array}$ & $\begin{array}{l}222 \\
101 \\
128\end{array}$ & $\begin{array}{l}49.22 \\
22.39 \\
28.38\end{array}$ & $0.001 *$ \\
\hline 4 & $\begin{array}{l}\text { While visiting Sabino Canyon, do you regularly participate in } \\
\text { activities such as organized outdoor events, public meetings, } \\
\text { social gatherings, nature walks? }\end{array}$ & $\begin{array}{c}\text { No } \\
\text { Yes, at least one } \\
\text { Yes, as an organizer }\end{array}$ & $\begin{array}{c}314 \\
104 \\
33\end{array}$ & $\begin{array}{c}69.62 \\
23.06 \\
7.32 \\
\end{array}$ & $0.000^{*}$ \\
\hline 5 & $\begin{array}{l}\text { How would you describe your willingness to financially } \\
\text { contribute to protect, restore, and enhance the natural } \\
\text { resources and recreation facilities at the SCRA? }\end{array}$ & $\begin{array}{l}\text { No fee } \\
\text { Willing to pay } \\
\text { Donation }\end{array}$ & $\begin{array}{c}55 \\
310 \\
86\end{array}$ & $\begin{array}{l}12.20 \\
68.74 \\
19.07 \\
\end{array}$ & $0.069^{*}$ \\
\hline 6 & $\begin{array}{l}\text { Would you be willing to volunteer your time to help protect, } \\
\text { restore and enhance the natural resources and recreation } \\
\text { facilities at the SCRA? }\end{array}$ & $\begin{array}{l}\text { No } \\
\text { Maybe } \\
\text { Yes }\end{array}$ & $\begin{array}{l}159 \\
164 \\
128\end{array}$ & $\begin{array}{l}35.25 \\
36.36 \\
28.38\end{array}$ & $0.000^{*}$ \\
\hline 7 & $\begin{array}{l}\text { If you noticed that one or more of the facilities at the SCRA } \\
\text { was in need of maintenance or repair, would you: }\end{array}$ & $\begin{array}{l}\text { Would not return } \\
\text { Ignore } \\
\text { Report to FS }\end{array}$ & $\begin{array}{c}5 \\
135 \\
311\end{array}$ & $\begin{array}{c}1.11 \\
29.93 \\
68.96\end{array}$ & $0.017 *$ \\
\hline 8 & $\begin{array}{l}\text { If you witnessed a fellow recreationist harassing or damaging } \\
\text { the natural resources at the SCRA, would you: }\end{array}$ & $\begin{array}{l}\text { Avoid situation } \\
\text { Report to FS } \\
\text { Educate } \\
\end{array}$ & $\begin{array}{c}35 \\
274 \\
142 \\
\end{array}$ & $\begin{array}{r}7.76 \\
60.75 \\
31.49 \\
\end{array}$ & $0.004 *$ \\
\hline 9 & $\begin{array}{l}\text { How important is recreation at the SCRA for your overall } \\
\text { quality of life? }\end{array}$ & $\begin{array}{l}\text { Not important } \\
\text { Moderately important } \\
\text { Very important }\end{array}$ & $\begin{array}{c}46 \\
176 \\
229\end{array}$ & $\begin{array}{l}10.20 \\
39.02 \\
50.78\end{array}$ & $0.012 *$ \\
\hline 10 & $\begin{array}{l}\text { How important do you believe the SCRA is for your local } \\
\text { community and its economy? }\end{array}$ & $\begin{array}{l}\text { Not important } \\
\text { Moderately important } \\
\text { Very important }\end{array}$ & $\begin{array}{c}20 \\
107 \\
324\end{array}$ & $\begin{array}{c}4.43 \\
23.73 \\
71.84\end{array}$ & $0.043^{*}$ \\
\hline
\end{tabular}


Table 2. Summary of Survey Responses: Socio-Demographic Questions (*= statistically significant)

\begin{tabular}{|c|c|c|c|c|c|}
\hline$\#$ & Question & Responses & No. & $\%$ & p-value \\
\hline 11 & How would you describe the place you grew up in? & $\begin{array}{l}\text { Rural/Small town } \\
\text { Suburban/Nearby city } \\
\text { Urban/City }\end{array}$ & $\begin{array}{l}164 \\
167 \\
120\end{array}$ & $\begin{array}{l}36.36 \\
37.03 \\
26.61\end{array}$ & 0.249 \\
\hline 12 & $\begin{array}{l}\text { How would you describe your geographic relationship with the } \\
\text { SCRA? }\end{array}$ & $\begin{array}{c}\text { Local } \\
\text { Seasonal } \\
\text { Out-of-town }\end{array}$ & $\begin{array}{c}253 \\
39 \\
159\end{array}$ & $\begin{array}{c}56.10 \\
8.65 \\
35.35\end{array}$ & $0.000^{*}$ \\
\hline 13 & How often do you visit the SCRA? & $\begin{array}{c}\text { Frequently } \\
\text { Occasionally } \\
\text { Rarely/First time }\end{array}$ & $\begin{array}{l}115 \\
210 \\
126 \\
\end{array}$ & $\begin{array}{l}25.50 \\
46.56 \\
27.94 \\
\end{array}$ & $0.000^{*}$ \\
\hline 14 & Which age range do you fall into? & $\begin{array}{c}\text { Under } 20 \\
21-35 \\
36-50 \\
51-65 \\
\text { Over } 65 \\
\end{array}$ & $\begin{array}{c}17 \\
113 \\
84 \\
165 \\
72 \\
\end{array}$ & \begin{tabular}{c|}
3.77 \\
25.06 \\
18.63 \\
36.59 \\
15.96 \\
\end{tabular} & $0.007 *$ \\
\hline
\end{tabular}

For the purposes of this study, the survey questions were designed to either define the individual's values surrounding the SCRA or to indicate other contributing factors that shaped the individual's values. Questions 1,2, 7 and 8 on the survey were designed to highlight the visitor's respect for all compositional elements of the SCRA (natural, built and social) as indicated by their behaviors and actions. Questions 5 and 6 showed the visitor's willingness to make a personal contribution of time or finances to provide additional support for sustaining the natural resources and recreation opportunities at the SCRA. Questions 9 and 10 asked the visitors to make a statement of value for the SCRA and the contributions it makes toward their wellbeing. Questions 3, 4, and 11 provided opportunities to explore the visitor's background, including past experiences and exposure to environmental education and other conservation learning activities. Questions 12 and 13 revealed the visitor's direct physical exposure to the SCRA, both temporally and spatially. Lastly, question 14 was strictly demographic and asked respondents to disclose their age within one of five possible age ranges. The following are responses to the four indicators of value: Respect, Willingness, Statement of Value and Other Contributing Factors.

\section{Respect}

The first question indicating the visitor's respect for the resources at the SCRA asked about their travel patterns. Among the overall group of respondents, $n=247$ individuals $(54.8 \%)$ replied that they only travel on designated roads and trails, indicating a respect for the natural resources by concentrating their use to minimize resource damage. There were $\mathrm{n}=193$ individuals $(42.8 \%)$ that responded that they mostly travel on trails but sometimes travel off-trail to visit unique features or favorite locations. There were $n=11$ respondents $(2.4 \%)$ that stated that they frequently travel off-trail.

The second question asked the respondents to describe their reaction when encountering wildlife in the SCRA. The majority $(58.1 \%)$ responded that they would take a picture from a distance, while 85 individuals $(18.9 \%)$ stated that they would attempt to go in for a closer look. There were $\mathrm{n}=104$ participants $(23 \%)$ that stated that if they saw unique wildlife in the SCRA, they would tell their friends and encourage others to visit SCRA for wildlife viewing. Not only does this response indicate the visitor's personal respect for the wildlife, it also shows their willingness to educate and inspire others to appreciate the unique features at the SCRA.

Another question designed to reveal visitor behavior asked respondents how they would react if they noticed that the facilities at the SCRA were in need of maintenance or repair. Most individuals $(69 \%)$ stated that they would report the incident to a Forest Service employee, with $\mathrm{n}=5$ individuals (1.1\%) stating that they would not return to the SCRA until these facilities were improved. There were $n=135$ people (29.9\%) that responded that although they may notice the facilities, they would continue on with their recreation activities. Those visitors that would formally make a report are showing their concern for the conditions of the facilities and their willingness to participate in the solution.

The final question surrounding visitors' respect for the resources asked the respondents how they would react if they witnessed a fellow recreationist harassing or damaging the natural resources at the SCRA. Again, the majority (60.8\%) stated that they would report the incident to a Forest Service employee or law enforcement officer. There were $n=35$ individuals $(7.8 \%)$ who would avoid the situation entirely. The results showed that $\mathrm{n}=142$ respondents $(31.5 \%)$ would try to educate the individual on the need to conserve and respect the natural resources at the SCRA. Although reporting the incident of vandalism would be a positive action, a high degree of personal stewardship is shown by those individuals who would voluntarily become educators in this situation.

\section{Willingness}

The survey asked two questions regarding the visitor's willingness to contribute to the sustainability of the SCRA. The first question asked the visitors to describe their willingness to financially contribute in an effort to protect, restore and enhance the natural resources and recreation facilities at the SCRA. Most participants $(68.7 \%)$ were willing to pay a standard fee at the SCRA knowing that these 
funds will go toward protecting the resources and enhancing recreation opportunities. There were $n=55$ respondents $(12.2 \%)$ that did not believe visitors should pay a fee, while $n=86$ respondents $(19 \%)$ were willing to donate beyond the standard fee to provide additional support to sustain the SCRA.

The other Willingness question asked visitors whether or not they would volunteer their time to the SCRA. Of the $\mathrm{n}=451$ respondents, the answers were closely divided between Yes (28.4\%), No (35.2\%) and Maybe (36.4\%). It may be inferred that those individuals who are fully willing to dedicate their time without financial compensation have a strong appreciation for Sabino Canyon.

\section{Statement of Value}

While other responses exposed the values of visitors through their behavior and reactions, there were two questions that directly asked visitors to state their values. The first question asked respondents to rate the importance of recreation at the SCRA for their overall quality of life. From the entire group of Forest Service, partner and public respondents, the majority $(50.8 \%)$ rated the SCRA as Very Important for their quality of life, with $10.2 \%$ responding that it was Not Important. $39 \%$ of the respondents ranked the SCRA as Moderately Important for quality of life.

A similar question asked participants to rate the importance of the SCRA for the local community and economy. There were $n=324$ individuals $(71.8 \%)$ that ranked it as Very Important, with $\mathrm{n}=107$ individuals $(23.7 \%)$ selecting Moderately Important and $n=20$ (4.4\%) responding with Not Important.

\section{Other Contributing Factors}

Visitors were asked several questions about their past experiences in an effort to examine the conditions or activities that may have potentially shaped their values and norms associated with public lands. Visitors were asked how many environmental education activities they had participated in throughout their lifetime. There were $n=128$ people $(28.4 \%)$ that had participated in more than two activities, with $n=101$ respondents $(22.4 \%)$ participating in $1-2$ activities. There were $n=222$ people $(49.2 \%)$ that have never participated in environmental programs.

A similar question asked respondents if they regularly participate in general outdoor activities or public land events, such as nature walks, national outdoor holidays, or other organized events at the SCRA. $23 \%$ percent of respondents said they have attended at least one of these kinds of activities. 69.6\% responded that they have never attended any of these activities. In contrast, there were $n=33$ individuals $(7.3 \%)$ that had not only participated, but sometimes convened these activities. While general participants demonstrate a basic willingness to learn, the organizers of these activities exhibit a willingness to spread awareness and encourage others to participate.

The last question that involved the respondents' background was packaged as a socio-demographic question; however, it also provides relevant information about the visitor's early life influences. The question asked whether the respondent grew up in a rural or small town, a suburban area or near to a city, or in an urban area within a city. The majority (37\%) grew up in a suburban area and $36.4 \%$ were raised in a rural or small town. The remaining $26.6 \%$ grew up in an urban area.

Two questions were asked to show the visitor's direct physical exposure to the SCRA. Visitors were asked where they live in relation to the SCRA and how often they visit the area. Of the $n=451$ respondents, $n=253$ (56.1\%) were local residents of Tucson. The results showed that $n=159$ respondents $(35.4 \%)$ lived outside of the Tucson area, with $\mathrm{n}=39$ visitors $(8.6 \%)$ living in Tucson strictly on a seasonal basis. There were $n=210$ visitors $(46.6 \%)$ that claimed to occasionally visit the SCRA, with $n=115$ (25.5\%) that frequently recreated in the area. The remaining $n=126$ respondents $(27.9 \%)$ stated that they either rarely visit the SCRA or it was their first time.

Lastly, respondents were asked to record their age within one of five possible age ranges. The majority of respondents (36.6\%) were between 51-65 years old, followed by 21-35 $(25.1 \%), 36-50(18.6 \%)$ and Over $65(16 \%)$. The youngest age range (Under 20) received the lowest percentage of participants $(3.8 \%)$.

\section{Discussion}

The purpose of this research was to explore the concept of social capital and its relationship to sustainability by studying the current visitors at the Sabino Canyon Recreation Area. The purpose of the Sabino Canyon Recreation Area is to sustain the ecologic functions of the environment while also providing satisfying recreation experiences to the public. This research quantifies the potential for social capital by measuring visitor values, a key feature required to build social capital.

\section{Social Capital Potential}

Results show that the foundations of social capital exist in the SCRA. The results for the overall group showed that potential can be found among $n=122$ people $(27 \%)$ at the SCRA. Based on their individual responses, these people are already demonstrating a positive relationship with the SCRA that adds to its sustainability. There were $n=310$ people overall (69\%) that are considered passive users of the SCRA. Given their current activity and values, these visitors are neither improving nor reducing the sustainability at the SCRA. There were $n=19$ people out of $n=451$ surveyed $(4 \%)$ that are currently demonstrating behaviors that negatively impact the SCRA.

The total population surveyed included $n=61$ Forest Service employees, $n=21$ partners, and $n=369$ members of the public. Among these three groups, the relative percentage of positive, neutral and negative users varied (Table 3). For social capital to be successfully applied to a recreation 
system, representatives from each of these groups must be involved in decision-making toward a sustainable future. For this reason, it is important to identify individuals from each group that demonstrate a positive relationship with the SCRA. In this study, it was critical to examine the relationships present among each of these groups and determine if there was a statistically significant difference between the user groups' responses. The results of statistical analysis show that in $71.4 \%$ of survey questions, the members of each respective user group provided responses that were significantly associated with their group affiliation. It is critical for managers to understand this association in order to address the issues that impede progress toward sustainability, including those issues within their own organization.

Table 3. Relationship Characterization by User Group

\begin{tabular}{|c|c|c|c|}
\hline User Group & Negative & Neutral & Positive \\
\hline FS & $3.3 \%$ & $68.8 \%$ & $27.9 \%$ \\
\hline Partner & $0 \%$ & $23.8 \%$ & $76.2 \%$ \\
\hline Public & $4.6 \%$ & $71.3 \%$ & $24.1 \%$ \\
\hline
\end{tabular}

The results show that the strongest potential for social capital exists in partner organizations. Because these individuals are already devoting their time through a voluntary partnership with the Forest Service, it logically follows that this user group would not require much further development to reach a level of social capital that benefits the SCRA. Among the partners, $76.2 \%$ demonstrated a positive, contributory relationship with the SCRA; this figure is more than double the percent of positive individuals in the Forest Service and public sectors. The percent of partners contributing to the SCRA is also greater than the percent of positive relationships found in the FS and public combined.

The majority of the general public fell into the Neutral relationship category. This passive relationship may be explained by the fact that over half $(52 \%)$ of the public respondents were either seasonal or out-of-town visitors and $82 \%$ of these individuals only visit the SCRA on a rare to occasional basis. While Forest Service employees and members of partner organizations are readily exposed to the SCRA, the public sector may have fewer opportunities to spend time outdoors. This reduced exposure may explain some of the negative scores from the public sector. From the public responses, $88 \%$ of the individuals that demonstrated negative behavior had rarely visited the SCRA and/or it was their first and only visit to the area. This figure should persuade managers to encourage more visitation to the SCRA as a way to increase the opportunities for the public to build a connection with nature. This goal could be accomplished through management strategies such as more fee-free days or increased community outreach.

As with the general public, the majority of Forest Service respondents had a neutral relationship with the SCRA. Unlike the public, the results cannot necessarily be explained by their level of exposure to the SCRA. Among the 61 employees, 93\% live in Tucson year-round. Despite their locality, just $46 \%$ of employees are frequently visiting the SCRA. This discrepancy may exist because the question did not distinguish between work-related exposure and personal recreation time. Other explanations may be that not all Forest Service employees are regularly field-going; many employees, particularly supervisors and managers, work primarily in offices. Another possible reason could be that Forest Service employees may want to avoid high density recreation areas like the SCRA and would prefer to recreate in dispersed areas away from crowds. In addition, some employees may not want to recreate in the same location that serves as their workplace.

Certain questions may have lowered the FS employees' overall relationship scores but may be explained by the nature of their employment. For example, only $13 \%$ of Forest Service respondents said they would be willing to volunteer their time; this is a logical conclusion given that employees already dedicate much of their time to protecting these resources as a component of their job. A better measure of the FS employees' relationship can been seen in the Respect questions, such as $82 \%$ of employees would report a facility in need of maintenance or repair.

\section{Implications for Management}

If managers are to fully benefit from social capital as a mechanism for enhancing sustainable recreation, they must first understand the qualities that influence the positive individuals. Of the 122 people that showed a positive relationship with the SCRA, 107 people $(88 \%)$ have attended at least one environmental education program. This statistic illustrates a strong link between environmental education and responsible recreation practices. Managers should interpret this information as a need for increased environmental education programming to enhance social capital and recreation sustainability. Similarly, $67 \%$ of the respondents that demonstrated an overall positive relationship have also attended organized outdoor activities at the SCRA, such as nature walks, social gatherings or public meetings. The relationship between these variables provides a basis for managers to argue for increased education and general community-based programming as a way to transition negative or neutral visitors to contributory visitors that positively affect the sustainability of the SCRA. These are critical action items for managers at the SCRA if they wish to build sustainability into their recreation services, given that the majority of current visitors are not involved in any of these programs.

Although most contributory visitors have participated in environmental programming, the majority of surveyed respondents demonstrated a general lack of substantive experience in conservation education. In addition, a large percentage of respondents live partly or completely outside of Tucson (43.89\%). Most respondents also have limited exposure to Sabino Canyon, visiting on a rare or occasional basis $(74.50 \%)$. If social capital is to become fully developed 
in the SCRA, managers must strategically target this large percentage of individuals that are uneducated in conservation principles and do not frequently interface with the area. These groups could be addressed by developing educational and outreach programs that enrich and enhance the experience of rare or occasional visitors. By specifically targeting this demographic, managers can positively influence these groups so that they remain interested and engaged in the sustainability of the SCRA long after their isolated visit.

The shared values examined in this study serve as the primary connector between the individuals recreating or working at the SCRA. Based on the presence of these features, managers could further develop social capital by unifying visitors that behave similarly and share the same values for the SCRA. Although just $27 \%$ of current visitors to the SCRA scored positively overall, $90 \%$ of the surveyed population made some statement of value for the SCRA. This large majority represents a key leverage point for managers; the first and greatest challenge in building social capital is to organize individuals around a common purpose. Although some actions may need to be adjusted, $90 \%$ of current visitors have already declared personal value for the area and therefore may only need education and encouragement to redirect their behavior. By uniting visitors around these shared values, managers may be able to catalyze the collective efforts of social groups to solve commonly-faced challenges in recreation management.

With the knowledge that potential exists among the current user group, managers must engage in what Albee and Boyd (1997) refer to as social preparation. The process of supporting groups of people to establish social capital involves five stages of action. For the SCRA, this research accomplishes the first and second steps: to gather information about the circumstances in the SCRA and to analyze the situation based on the resources present. The next steps for managers would be to prioritize actions and then to join together those individuals that share common values for the SCRA. Once a formal organization has occurred, managers could facilitate the effort to plan implementation of these desired actions. This fundamental process of participatory development is essential in developing social capital. The initial assessment of potential in the SCRA was a critical step, as noted by Munkner (1979) in his review of self-help groups. Munkner argues that a common flaw in policy development is the attempted establishment of structured community groups without first conducting an assessment of local conditions to gauge the readiness of these individuals for organization.

Another approach to building social capital from the current potential may be to increase the number of learning events that highlight the benefits of recreation and allow community members to become directly involved in the management of the SCRA. According to Falk and Kilpatrick (1999), social capital can be accumulated as a result of meaningful learning interactions; these educational moments are often a necessary precondition to building social capital.
As opposed to traditional education and acquisition of knowledge, learning events have the ability to change an individual's perspective on a situation through significant moments of enlightenment and recognition. In a socio-ecological system, learning events may help the individual to realize their own ability to influence the sustainability of the system. An example of these learning interactions may involve community members and recreationists participating in the planning and implementation of projects that benefit and sustain the recreation area. The outcome of this learning process is an interactive productivity amongst local networks of people that generates collaborative solutions and socially-driven changes (Falk and Kilpatrick 1999).

\section{Conclusions}

The goal of this research was to measure the potential to build social capital amongst the visitors currently recreating in the Sabino Canyon Recreation Area as a means of contributing to the overall sustainability of the place and its recreation opportunities. This study answers the following four research questions:

1. Is there a tangible connection between social capital and sustainability?

Yes. The application of social capital in sociology, economics, and other disciplines has established a link between social capital and sustainability through the production of shared benefits that support the continued functioning of the system.

2. Can the concept of social capital be applied to natural resource management, specifically in the context of recreation?

Yes. Although this research represents the inaugural effort to link social capital and recreation, these socio-ecological systems contain the fundamental components of social capital through the values carried by the visitor.

3. What are the components of social capital that can be measured and how?

Measurable characteristics of social capital include trust, values, and networks. Values can be measured through declared willingness, admitted statements of value, and respect as indicated through individual actions and behaviors.

4. Is there potential to build social capital in the group that currently uses Sabino Canyon?

Yes. Those important features of social groups that give individuals the ability to work together for a common purpose are present in the group that currently uses the SCRA. The individuals who exhibit these qualities may also be enlisted to further develop social capital in the visitors that are currently not contributing to the sustainability of the SCRA. 
Fully-developed social capital at the SCRA would ideally include an organized group of sustainably-minded, responsible, and respectful citizens that are passionate and interested in collaborating to develop mutually beneficial solutions for today's recreation challenges. The benefits of social capital will be fully realized as recreation managers become the leaders in uniting these individuals around their common identity and shared interests to build a mutual commitment to the sustainability of the SCRA.

The results of this research led to several general conclusions about the potential for social capital development in the Sabino Canyon Recreation Area. Based on the survey results, the majority of respondents:

1. Seek to minimize their resource damage by travelling primarily on designated trails and roads.

2. Respect and value the wildlife, and make efforts not to disturb or frighten animals in their natural setting.

3. Have not participated in any environmental education programs.

4. Have not attended any of the organized outdoor activities or events at the Sabino Canyon Recreation Area.

5. Support a recreation fee but would not necessarily be willing to make a donation above the base fee.

6. Hesitate to fully commit to volunteering their time to the Forest Service.

7. Care about the appearance and function of the recreation facilities.

8. Feel a sense of responsibility in protecting the natural resources from vandalism.

9. Believe that recreation at the SCRA is very important for their overall quality of life.

10. Feel that these same recreation opportunities are very important for their local community and its economy.

While the majority of users characterized recreation as valuable for the quality of their community, economy and personal lives, most users were not engaging with the recreation area in a way that sustains the system. Those participants that scored positively on the Social Capital Scale exhibited both the values and behaviors necessary to support the system over time. Based on these results, we can conclude that social capital may be developed through the propagation of these behaviors, motivated by the values held in common by the majority.

Although many researchers have found it challenging to measure social capital given its complex and abstract nature, we focused on values as the indicator to assess social capital at the foundational level. This research represents an application of social capital theory that shows the importance of context in materializing abstract components into practical operations. Historically, the concepts surrounding this theory have been heavily debated when the discussion lacks a concrete framework; this research contextualizes social capital within a recreation space, allowing researchers to identify and measure features introduced by the visitors. In framing these concepts within a socio-ecological system, we have solidified the central premise of social capital theory.
Values, a social feature that predisposes people towards mutually beneficial actions, can serve as an important resource in maintaining a sustainable system.

This exploration of social capital theory, coupled with precedents set in related fields, affirms that creating social capital could potentially solve shared problems within systems or disciplines that contain a strong human element. Based on this research and other studies highlighting social capital as a positive reserve of social values, recreation managers can use relationships to enhance the sustainability of recreation areas. Furthermore, these conclusions should strongly encourage managers to move away from a transactional model that characterizes the visitor's relationship with the land as an exchange of fees for experiences. Social capital provides a mechanism through which managers can build a meaningful relationship between individuals, social groups and natural areas. Establishing and enhancing human connections with nature through stewardship allows for continued ecosystem benefits for individuals and local communities and the special places that are held in common for present and future generations.

Subsequent studies connecting social capital and recreation could be carried out in national parks, national forests, or any other publicly-managed lands designated for recreational use. As with this study, it will be critical for managers to first identify positive features amongst their visitors and then to understand the experiences that influence those individuals that are actively contributing to the sustainability of recreation places. This scientific approach could be further refined and expanded upon by measuring additional features of social capital, such as networks and trust within social groups. Future extensions of this research may also assess non-user motivations and explore methods for attracting members of society that are not currently using their public lands. Although this study evaluates social capital characteristics at the individual level, the scope of future studies could be expanded by extending the sample population to the community level. Successive studies may also explore the network component of social capital by engaging the contributory visitors in recreation spaces to reach out to other communities and encourage public reciprocity through stewardship.

\section{REFERENCES}

[1] Albee, A. \& Boyd, G. (1997). Doing it differently: Networks of community development agents. Scottish Community Education Council, Edinburgh, Scotland.

[2] Adler, P.S., \& Kwon, S.W. (2002). Social capital: Prospects for a new concept. Academy of Management. The Academy of Management Review 27, 17-40.

[3] Bodin, O., \& Crona, B. (2008). Management of natural resources at the community level: Exploring the role of social capital and leadership in a rural fishing community. World Development 36, 2763-2779. 
[4] Boxman, E.A.W, De Grant, P.M. \& Flap, H.D. (1991). The impact of social and human capital on the income attainment of dutch managers. Social Networks 13, 51-73.

[5] Cavaye, J. (2004). Social capital: A commentary on issues, understanding and measurement. Australia: Observatory PASCAL - Place Management, Social Capital and Learning Regions.

[6] Chapin, F. S, G. P. Kofinas, C. Folke. 2009. A Framework for Understanding Change. In F. Stuart Chapin, Gary P.Kofinas, Carl Folke, editors. Principles of Ecosystem Stewardship, Resilience -Based natural Resource management in a Changing World. Springer-Verlag New York. 2009

[7] Claridge, T. (2004) Social capital and natural resource management: An important role for social capital?

[8] Collier, P. (2002). Social capital and poverty: A microeconomic perspective. The Role of Social Capital in Development, edited by Thierry Van Bastelaer. Melbourne: Cambridge University Press. $19-41$.

[9] Compton, E. \& Beeton, R.J.S. (2012). An accidental outcome: Social capital and its implications for Landcare and the "status quo". Journal of Rural Studies.

[10] Corder, G.W. \& Foreman, D.L. (2009). Nonparametric statistics for non-statisticians. John Wiley and Sons. Hoboken, NJ.

[11] Daniere, A., Takahashi, L.M., \& NaRanong, A. (2002). Social capital and environmental management: culture, perceptions and action among slum dwellers in Bangkok. Social Capital and Economic Development: Well-being in Developing Countries, edited by Sunder Ramaswamy. Cheltenham, UK: Edward Eglar.

[12] de Wit, M.P. \& Blignaut, J.N. (2000). A critical evaluation of the capital theory approach to sustainable development. Agrekon, 39, No. 1 .

[13] Falk, I. \& Kilpatrick, S. (1999). What is social capital? The study of interaction in a rural community. Launceston: Centre for Research and Leaning in Regional Australia.

[14] Fukuyama, F. (1997). Social capital and the modern capitalist economy: Creating a high trust workplace. Stern Business Magazine 4.

[15] Grootaert, C., Van, B. T., \& World Bank. (2002). Understanding and measuring social capital: $A$ multidisciplinary tool for practitioners. Washington, D.C: World Bank.

[16] Henocque, Y. (2013). Enhancing social capital for sustainable coastal development: Is satoumi the answer? Estuarine, Coastal and Shelf Science 116 (2013) 66-73.

[17] Krishna, A. \& Uphoff, N. (2002). Mapping and measuring social capital through assessment of collective action to conserve and develop watersheds in Rajasthan, India. The Role of Social Capital in Development, edited by Thierry Van Bastelaer. Melbourne: Cambridge University Press. 85 $88,115-124$.

[18] Liu, A.Q. \& Besser, T. (2003). Social capital and participation in community improvement activities by elderly residents in small towns and rural communities. Rural Sociology 68: 343.
[19] Munkner, H.H. (1979), Co-operatives and rural poverty, Marburg, Federal Republic of Germany

[20] Murdock, E. (2012). (DRAFT) A field guide for collecting monitoring data for indicators of the visitor experience at Devils Postpile National Monument.

[21] Narayan, D., \& Cassidy, M. F. (2001). A dimensional approach to measuring social capital: Development and validation of a social capital inventory. Current Sociology, 49, 59-102.

[22] Pilkington, P. (2002). Social capital and health: Measuring and understanding social capital at a local level could help to tackle health inequalities more effectively. Journal of Public Health Medicine 24: 156-159.

[23] Poe, A. \& H. R. Gimblett (eds). Sustainable Wildlands: A Prince William Sound Case Study of Science-based Strategies for Managing Integrating Science and Community Perspectives in Prince William Sound: a Case Study on Managing for Sustainable Use of Wildlands. University of Arizona Press. 2015. (Forthcoming).

[24] Pretty, J. \& Ward, H. (2001). Social capital and the environment. World Development 29: 209-227.

[25] Public Lands Interpretive Association (PLIA). (2011). (Brochure). Trails of Sabino Canyon, Coronado National Forest, Arizona.

[26] Putnam, R.D. (1995). Bowling alone: America's declining social capital. Journal of Democracy 6: 65-78.

[27] Putnam R.D., Feldstein, L., \& Cohen, D. (2003). Better together: Restoring the American community. New York: Simon \& Schuster.

[28] Ritchie, M. (2000). Social capacity, sustainable development, and older people: Lessons from community-based care in Southeast Asia. Development in Practice 10: 638-651.

[29] Robison, L.J., Schmid, A.A., \& Siles, M.E. (2002). Is social capital really capital? Review of Social Economy 60: 1-24.

[30] USDA Forest Service - Recreation, Heritage and Volunteer Resources. (2010a). Connecting people to America's great outdoors: A framework for sustainable recreation.

[31] USDA Forest Service. (2010b). Trails analysis: Incorporating the sustainable recreation framework.

[32] USDA Forest Service. (2012a). (Brochure) A framework for sustainable recreation.

[33] USDA Forest Service, Southwestern Region. (2012b). A strategy for southwestern sustainable recreation.

[34] USDA Forest Service. (2012c). (DRAFT) Implementation guide to the framework for sustainable recreation.

[35] USDA Forest Service. (2013). Forest Service Handbook 1909.12 (Proposed). Land management planning handbook. Washington, DC: USDA Forest Service.

[36] Valenzuela, F. (2013). (DRAFT) Sustainable recreation and tourism planning. USDA Forest Service, Southwestern Region. 